\title{
A POLÍTICA DA INTOLERÂNCIA E OS DISCURSOS REPRESSIVOS JUSTIFICADORES DA PENA
}

\section{Andressa Tanferri Sentone*}

\section{RESUMO}

O presente artigo objetiva analisar de forma crítica os discursos repressivos que crescem no país, buscando o recrudescimento das leis penais e maior intervenção do estado. Para tanto, o estudo abordará os discursos legitimadores da pena e na sequência, os fundamentos da ideologia da defesa social e como ela é utilizada como instrumento simbólico de proteção da população que vive em uma constante de medo. Ao final, o trabalho demonstrará como tais discursos vêm sendo utilizados como bandeira política, pautados na importação de teorias como Lei e Ordem e Tolerância Zero e a falibilidade desses discursos frente à realidade brasileira.

Palavras-Chave: Legitimação da pena. Defesa social. Discursos repressivos. Punição. Política.

\section{THE INTOLERANCE'S POLITICS AND THE REPRESSIVE SPEECHES THAT JUSTIFYING THE PENALTY}

\begin{abstract}
The present article critically analyzes the repressive speeches that grow in the country, which looks for criminal laws more severe and greater state intervention. The study will address the legitimating speeches of the feather and the foundations of the social defense's ideology and how it is used as a population's protection symbolic instrument that lives in a constant fear. In the end, the work will demonstrate how these speeches have been used as political banner, based on the theories' importation such as Law and Order and Zero Tolerance and the fallibility of these discourses in front of the Brazilian reality.
\end{abstract}

Keywords: Penalty's Legitimacy. Social defense. Repressive speeches. Punishment. Politics.

\section{INTRODUÇÃO}

A violência oriunda da criminalidade é uma das maiores preocupações da sociedade nos tempos atuais, especialmente no Brasil, onde os índices de criminalidade se mostram em crescimento, noticiários inundam as residências da população com manchetes violentas, as pessoas mudam seus hábitos e se isolam cada vez mais em locais que aparentam ser mais protegidos, tudo em prol de uma pseudo segurança.

\footnotetext{
* Mestranda em Ciência Jurídica pela UENP, especialista em Direito e Processo Penal (UEL). Docente do Curso de Graduação em Direito da Universidade Pitágoras-Unopar, Londrina/PR. Advogada, andressatanferri@gmail.com
} 
Nesse contexto, o medo, capaz de manipular comportamentos, vem sendo utilizado como instrumento político para ascensão e manutenção do poder. Superando as tradicionais pautas de educação e saúde, o governo, especialmente os candidatos ao governo, têm apostado em discursos de defesa social onde o jus puniendi é utilizado, em nome da sociedade, como aparelho de repressão a comportamentos tidos como desviantes e que ameaçam de alguma forma a ordem social.

Os discursos legitimadores da pena justificam o sacrifício da liberdade em prol da harmonia social e foram pautados em diversos interesses ao longo dos tempos, como a vingança, a exploração do trabalho, a correção e a ressocialização, porém, a defesa social, cuja origem remonta à Escola Clássica, pode ser considerada como elemento fundamental da pena que persiste até os dias atuais.

Pautados na ideia tradicional da Defesa Social, verifica-se a ampliação do discurso penal repressivo, influenciado por teorias como a Lei e Ordem e a Tolerância Zero, onde a punição apresenta-se como solução ilusória para as mazelas sociais. O efeito simbólico da criação de novos tipos penais, bem como de atitudes austeras por parte do Estado produzem na sociedade uma falsa sensação de segurança, quando na verdade o que se verifica é a abertura de um campo para comportamentos abusivos, discricionários e seletivos do Estado.

Dentro desse contexto, o objetivo do presente estudo consiste, portanto, em analisar a construção desses discursos punitivistas que referem-se ao próprio surgimento da pena e suas pautas legitimadoras, em especial a abordagem da defesa social como justificativa para o castigo e a atuação defensiva do Estado. No mais, de forma crítica, busca-se ponderar como estes argumentos podem ser explorados como discurso político e utilizados de forma a cercear a liberdade da população, resultando na aplicação distorcida da lei e convertendo o Estado democrático em autoritário.

O método escolhido para desenvolver a pesquisa, de caráter eminentemente teórico, foi o dedutivo, com revisão bibliográfica e documental, partindo de premissas gerais e verdadeiras relacionadas à defesa social e dos demais discursos legitimadores da pena e objetivando chegar a uma conclusão relativa à má utilização destas justificativas para intervenção arbitrária do Estado.

\section{DISCURSOS LEGITIMADORES DO SISTEMA PUNITIVO}


O direito penal, diante do crescimento da sensação generalizada de desconfiança e desordem social, é apresentado simbolicamente como um verdadeiro aparato de defesa do cidadão e instrumento imprescindível na manutenção do controle social e prevenção da criminalidade. A promoção desta imagem pode ser atribuída notadamente a interesses políticos de legitimação de poder, bem como à forte influência da mídia na formação de opinião em massa.

Segundo Zaffaroni, a legitimidade do sistema penal pode ser entendida como "a característica outorgada por sua racionalidade", ou seja, o sistema penal se apresenta utopicamente como um "exercício de poder planejado racionalmente", entretanto, esta racionalidade não se sustenta pela falta de coerência e veracidade em sua aplicação prática. (ZAFFARONI, 1927, p. 16).

Com o aumento da popularidade do direito penal crescem também os discursos punitivistas que defendem a criminalização de novas condutas, o agravamento das penas existentes, a ampliação da intervenção estatal e até mesmo a possibilidade de aplicação de penas severas proibidas constitucionalmente no ordenamento jurídico pátrio, ainda que em flagrante retrocesso social, como se a "inflação do direito penal", também chamado de panpenalismo, pudesse solucionar o problema da criminalidade moderna.

Nesse diapasão se insere o chamado "direito penal simbólico", que consiste no conjunto de normas penais elaboradas no clamor da opinião pública, suscitadas geralmente na ocorrência de crimes violentos, envolvendo pessoas famosas, com grande repercussão na mídia, dada a atenção para casos determinados, específicos e escolhidos sob o critério exclusivo dos operadores da comunicação, objetivando escamotear as causas históricas, sociais e políticas da criminalidade, como se a a única resposta para a segurança da sociedade a criação de novos e mais rigorosos comandos normativos penais.

Este discurso, no entanto, não é atual, e busca no Direito Penal a solução para o problema da criminalidade, rememorando os discursos legitimadores da própria pena, que perpassam pela ideia de vingança, suplício, onde o mal somente poderia ser retribuído com outro mal, posteriormente, à escravidão dos aprisionados e a exploração dos trabalhos

\footnotetext{
${ }^{1}$ Este termo é usado para caracterizar dispositivos penais "que não geram, primariamente, efeitos protetivos concretos, mas que devem servir à manifestação de grupos políticos ou ideológicos através da declaração de determinados valores ou o repúdio a atitudes consideradas lesivas. Comumente, não se almeja mais do que acalmar os eleitores, dando-se, através de leis previsivelmente ineficazes, a impressão de que está fazendo algo para combater ações e situações indesejadas" (ROXIN, p. 2006, 47).
} 
forçados, até a ideia correcionalista que busca corrigir o comportamento do indivíduo embasando a sua legitimidade nas ideias de ressocialização e prevenção.

Com a intenção de traçar uma linha paralela entre a criminalidade e o sistema punitivo, não é possível definir, ao certo, o marco temporal da origem da pena, mas afirma-se que a sua utilização é tão antiga quanto a própria humanidade. Já a pena privativa de liberdade considerada como sanção penal pode ser atribuída ao século XVIII. Antes disso, é possível encontrar alguns resquícios de correção e moralização de delinquentes através da pena de prisão, porém, durante vários séculos ela servia apenas como depósito daqueles que aguardavam o julgamento com a aplicação da verdadeira pena, que poderia consistir em penas de morte, corporais, infamantes e de trabalhos forçados. (BITENCOURT, 2011, p. 27-28).

Quando passou a funcionar como sanção, os fundamentos iniciais da pena se encontravam no mercantilismo e exploração de mão de obra, sem critérios definidos para determinar a sua duração e sequer a sua própria aplicação, assim, por não haver uma concepção adequada do relacionamento entre punição e crime, as sentenças eram desproporcionais em sua maioria (RUSCHE e KISCHHEIMER, 2004, p. 109).

$\mathrm{Na}$ idade moderna, calcados nas bandeiras do Iluminismo e com ideias que influenciaram diretamente o movimento revolucionário francês, filósofos, moralistas e juristas se insurgiram contra as concepções arbitrárias e incertas da legislação penal vigente, demandando por condições de cumprimento da pena que respeitassem as liberdades e a dignidade do indivíduo. (BITENCOURT, 2011, p. 52).

Neste contexto foi escrita a obra "Dos Delitos e das Penas" de Marquês de Beccaria, que serviu como um marco de mudança na visão, função e aplicação das penas. A obra de 1764, que orienta até os dias de hoje a aplicação da pena e o processo penal, defendeu a formalização do direito processual e substantivo por meio da utilização de princípios basilares nos julgamentos, como a legalidade, a proporcionalidade, a imparcialidade do juiz, a presunção de inocência, a igualdade, sob a justificativa de que "todo exercício do poder que deste fundamento se afastar constitui abuso e não justiça; é um poder de fato e não de direito; constitui usurpação e jamais um poder legítimo" (BECCARIA, 2007, p. 19-20).

Sob a influência das ideias de Beccaria e outros expoentes do período, como Voltaire, Montesquieu, Benthan, no início do século XIX inicia-se a fase de humanização da pena, 'esse movimento tinha por raiz a palavra 'humano', o que significava que o homem era colocado no centro do universo, na condição de atenção de todas as preocupações políticas, econômica e sociais" (ANITUA, 2008, p. 70). 
Nesses moldes, a utilidade comum e o contrato social são a base da justiça humana, o contrato legitima o exercício do poder punitivo pelo próprio Estado e justifica o sacrifício necessário de parte da liberdade individual em prol da máxima felicidade do maior número. $\mathrm{O}$ dano social constitui, pois, a essência e a medida do delito no direito penal e a defesa social constitui o elemento fundamental da teoria da pena (BARATTA, 1999, p. 34-35).

No anos do século XVIII e na primeira metade do século XIX, após a contribuição de Cesare Beccaria, desenvolveram-se os estudos da Escola Clássica Criminal, também chamada idealista, filosófico-jurídica ou crítico-forense, que, fazendo uso do método lógicoabstrato ou dedutivo, fundamenta-se no livre-arbítrio, de matizes invidualista e liberal, considerando o crime como instituto jurídico e a pena, meio retributivo. Para os clássicos, a pena é uma retribuição jurídica à violação voluntária do contrato causa pelo sujeito, que tem como objetivo o restabelecimento da ordem jurídica violada. (SHECAIRA, p. 86).

Mais de um século após a publicação da obra de Beccaria, Cesare Lombroso, sucedido por Enrico Ferri e Rafael Garofalo, publica a obra L'uomo delinquente e inaugura um novo período denominado científico e que marca o início da Escola Positiva (SHECAIRA, p. 87-88). Conforme Roberto Lyra (1956, p. 6): “a Escola Positiva, também chamada italiana, nova, moderna ou antropológica (Lombroso, Ferri, Garofalo, Fioretti), é determinista e defensivista, encarando o crime como fenômeno social e a pena como meio de defesa da sociedade e de recuperação do indivíduo.”.

De fato, a incessante busca intelectual por uma justificativa para o porquê de punir é uma questão de alta relevância e de inegável atualidade, pois envolve a legitimação e os limites do poder estatal. Deve-se ter em mente, de forma clara, com base em quais pressupostos justifica-se que o Estado prive a liberdade de algum de seus cidadãos ou intervenha de outro modo, restringindo os seus direitos, para que a atividade estatal não descambe em puro arbítrio (ROXIN, 2006, p. 15).

Apesar da aparente transição realizada ao longo dos últimos dois séculos de uma política penal repressivista para uma ideia mais liberal e progressista de punição, observa-se que os problemas inerentes às ordens sociais atuais e a própria consciência social dos indivíduos impedem uma atividade de reforma verdadeiramente construtiva. Assim, acaba por prevalecer a ideia culturalmente arraigada no pensamento humano de que a punição é o caminho mais eficaz para a manutenção da ordem social: 
A consequência fatal é um retorno à doutrina pessimista de que a natureza perversa do homem só pode ser contida através da degradação do nível das prisões abaixo do das classes subalternas livres. A futilidade da punição severa e o tratamento cruel podem ser testados mais de mil vezes, mas enquanto a sociedade não estiver apta a resolver seus problemas sociais, a repressão, o caminho aparentemente mais fácil, será sempre bem aceita (RUSCHE e KISCHHEIMER, 2004, p. 282).

Contudo, diante dessa desconstrução das funções do direito penal, a ele têm aderido discursos que, em verdade, reforçam e pregam a segregação, o extermínio e a neutralização dos criminalizados. Frases como "bandido bom é bandido morto" no campo do senso comum, decorrentes de um populismo penal midiático, ou as declarações como do "direito penal do inimigo" no campo jurídico, que pressupõe um tratamento mais rigoroso aos violadores da norma penal, têm sido reproduzidos para justificar e até mesmo prescrever a forma atual de funcionamento desse sistema penal seletivo.

Essa é a grande celeuma que circunda o próprio conceito da pena na atualidade, notadamente se exerce as funções para as quais foi pensada (prevenção geral e especial) ou se o seu discurso encontra bases na dominação e de manutenção do poder. Conforme será demonstrado adiante, o discurso punitivo encontrou na política um campo fértil para reproduzir esta ânsia punitiva denominada populismo penal, como se esta fosse a resposta de toda a complexidade real da criminalidade, com fundamento na Escola da Defesa Social, no movimento Lei e Ordem e no Direito Penal do Inimigo.

\section{A IDEOLOGIA DA DEFESA SOCIAL E OS PRINCÍPIOS FUNDAMENTADORES DA PENA}

O discurso da defesa social é utilizado para legitimar a aplicação da pena e aparece no cenário das ciências penais pregando a reação estatal frente à periculosidade do delinquente. Representada inicialmente por Von Liszt, a teoria defendia que a pena deveria garantir de forma mais efetiva possível a defesa da sociedade, rejeitando a imposição de penas insuficientes, rotineiramente abrandadas pela indulgência dos tribunais.

A missão do direito penal seria a luta contra a criminalidade, vista como fenômeno social, visando garantir, da melhor maneira possível, a proteção aos bens jurídicos tutelados pela norma penal. "O dano social e a defesa social constituem, neste sistema, os elementos fundamentais, respectivamente, da teoria do delito e da teoria da pena" (BARATA, 1999, p. $34)$. 
Nesse sentido, a defesa social consistiria em um movimento de política criminal fundamentado em uma visão de defesa da sociedade em primeiro lugar, consolidando a posição do Estado nesse cenário, onde todas as ações de repressão devem voltar-se exclusivamente sobre a pessoa do autor, uma espécie de Direito Penal Subjetivo, em detrimento do tradicional Direito Penal do Fato (OLIVEIRA, 2009, p. 93-94).

Destaca-se que o termo ideologia é utilizado aqui em seu sentido negativo, para expor uma falsa crença, que legitima instituições sociais atribuindo-lhes funções ideais diversas das realmente exercidas, especialmente no que diz respeito às "idealizações mistificantes das funções reais dos institutos penais", identificada como ideologia da defesa social (BARATTA, 1999, p. 46).

Esta ideologia baseia-se na ideia de que a sociedade deve reagir em defesa da manutenção do bem-estar social contra qualquer ataque que ameace a sua conservação, sendo assim, a pena nada mais é do que um instrumento defensivo em resposta às investidas da criminalidade, nesse sentido conceitua Andrade:

\footnotetext{
Nestas condições, se o homem está fatalmente determinado a cometer crimes, a sociedade está igualmente determinada - através do Estado - a reagir em defesa de sua própria conservação, como qualquer outro organismo vivo, contra os ataques às suas condições normais de existência. A pena é, pois, um meio de defesa social. Contudo, na defesa da sociedade contra a criminalidade, a prevenção deve ocupar o lugar central, porque muito mais eficaz do que a repressão (ANDRADE, 2015, p. $38)$.
}

Depreende-se, pois, que a defesa social constitui o fundamento dos discursos repressivos ligados ao sistema penal, direcionando sua atuação ao autor do delito, sendo que a medida da pena era sopesada com base no determinismo e na potencial periculosidade social do agente (ANDRADE, 2015, p. 39).

Nesse diapasão, a escola da defesa social, forjada por experiências penais e criminológicas, abdicou do convencional projeto de responsabilização do sujeito pelos resultados externos da ação (direito penal do fato) para submetê-lo à aplicação judicial da pena lastreada em suas condições pessoais, tais como sua história e suas opções de vida (direito penal de autor). (CARVALHO, 2014, p. 219).

A posteriori, com a adoção e consolidação de um direito penal do fato, a teoria da defesa social precisou ser reformulada a fim de conciliar um direito penal que ao mesmo tempo tivesse legitimidade para intervir sobre a "personalidade perigosa" do indivíduo e para 
proteger as seus direitos fundamentais, "daí em diante convivem o discurso de garantia do indivíduo com o discurso da defesa social; o discurso do homem como limite do poder punitivo e o discurso do homem como objeto de intervenção positiva desse mesmo poder, em nome da sociedade" (ANDRADE, 2015, p. 40).

Baratta faz uma reanálise da ideologia da defesa social condensando-a em princípios que são aplicados para fundamentar a pena, sendo que ao longo do seu livro Criminologia Crítica e Crítica do Direito Penal dedica um capítulo específico para negar cada um destes princípios, analisando os argumentos que os negam:

a) Princípio de legitimidade: a sociedade atribui um poder legítimo ao Estado, que o exerce por meio das instâncias oficiais de controle social, tornando-o detentor do jus puniendi, cuja função é combater a criminalidade e manter a ordem social.

b) Princípio do bem e do mal: este princípio divide a sociedade em dois grupos, os cidadãos de bem, respeitadores dos valores sociais e os desviantes, que representam o elemento negativo. Esse princípio representa basicamente a noção de "Direito Penal do Cidadão e Direito Penal do Inimigo" de Jakobs ${ }^{2}$.

c) Princípio de culpabilidade: há um paralelo entre a culpabilidade inerente ao crime e os delitos naturais, que seriam considerados comportamentos reprováveis pela sociedade antes mesmos de sua tipificação no ordenamento jurídico.

d)Princípio da finalidade ou da prevenção: a finalidade da pena vai além da retribuição e deve exercer precipuamente a função ressocializadora.

e) Princípio de igualdade: as leis, especialmente as penais, devem ser aplicadas igualitariamente para todos, portanto, qualquer um que praticar uma violação estará sujeito às sanções previstas.

f) Princípio do interesse social e do delito natural: as condutas penais tipificadas são àquelas eleitas de acordo com o interesse social, a fim de tutelar os bens jurídicos considerados mais relevantes pela sociedade como um todo.

Na crítica à ideologia da defesa social, Baratta aponta a importância dos meios alternativos de controle, não menos rigorosos, mas que podem se mostrar mais eficazes, furtando-se de cair em uma política reformista que consiste em simples extensão do direito

\footnotetext{
${ }^{2}$ [...] o Direito penal conhece dois polos ou tendências em suas regulações. Por um lado, o tratamento com o cidadão, esperando-se até que se exteriorize sua conduta para reagir, com o fim de confirmar a estrutura normativa da sociedade, e por outro, o tratamento com o inimigo, que é interceptado já no estado prévio, a quem se combate por sua periculosidade (JAKOBS, 2005, p. 37).
} 
penal e que legitima o sistema repressivo tradicional. Neste sentido, destaca-se a proposta de uma política criminal alternativa ao direito penal desigual, uma reforma do processo, da organização judiciária, da polícia, além da substituição de sanções penais por formas de controle não estigmatizantes, a fim de reduzir a criminalização seletiva que opera em níveis institucionais e propagar o desenvolvimento de formas mais humanas de vida comunitária (BARATTA, 1999, p. 202-203).

A intervenção exacerbada do Estado no âmbito da repressão e da punitividade, ainda que justificada pela defesa da sociedade demonstra radical potência para romper com a legalidade e produzir ofensa aos direitos fundamentais, em especial à liberdade (CARVALHO, 2014, p. 227). Nesse trilhar, qualquer forma de repressão estaria legitimada em nome do combate aos maus:

Se, de um lado, a defesa social exprime a ideia de proteção da sociedade contra o crime e os criminosos, por outro lado, coloca a questão da criminalidade como algo que precisa ser combatido, exprimindo-se a ideia de guerra, de "luta contra o crime". Nesse enfoque, pressupõe-se que a sociedade é dividida entre indivíduos bons (pessoas de bem) e maus - perigosos, criminosos, por conseguinte transforma os réus em inimigos da sociedade, contra os quais estariam justificadas todas as formas de repressão (SANTOS, 2010, p. 10).

Dessume-se, ainda, que o discurso da defesa social é bastante sedutor, pois encontra respaldo na ideia de proteção de bens jurídicos para fundamentar o aumento da intervenção do poder punitivo estatal, mas, por outro lado, também serve de instrumento para facilitar a ampliação de ideologias repressivas e simbólicas que caracterizam Estados distintos dos democráticos (GOMES, 2008, p. 17). Segue-se, no particular, o entendimento de Pavarini:

\begin{abstract}
A defesa social reivindica o mérito de haver liberado a política criminal (e em particular a penal) das hipotecas de velhas interpretações transcendentes e míticas e de havê-la reconduzido a uma prática científica através da qual a sociedade se defende do crime. A defesa social é, portanto, uma ideologia extremamente sedutora, enquanto é capaz de enriquecer o sistema repressivo (vigente) com os atributos da necessidade, da legitimidade e da cientificidade (Pavarini, 1988, p. 49).
\end{abstract}

Destaca-se que a defesa social analisada de forma crítica no presente trabalho não se confunde com a ideia trazida pela teoria intitulada de "Nova Defesa Social", segundo a qual há uma mudança nos postulados da punição, pois o objetivo passa a ser somente a proteção da sociedade frente às ações delituosas e não a punição do agente que as praticou. "A expressão "Défense Social" significa hoje o conceito abrangente de todas as medidas da sociedade 
contra delinquentes e apenados, que tem a finalidade de ressocializar estas pessoas" (ASHTON, 1996, p. 245).

As ideias da Nova Defesa Social, defendidas principalmente por Marc Ancel, buscam atualizar, melhorar e humanizar a atividade punitiva estatal, primando por um exame crítico das instituições penais vigentes e distanciando-se da função retributiva da pena para abraçar a ideia da ressocialização, considerando um tratamento humano e que leve em consideração as garantias fundamentais do preso.

A legislação atual, por outro lado, distancia-se da corrente moderna de defesa social ao pregar o agravamento das sanções penais e a limitação de garantias constitucionais, a exemplo da Lei dos Crimes Hediondos. Conforme defende Baratta, a pena não pode ser o único meio de defesa social; antes, o maior esforço da sociedade deve ser aplicado na prevenção do delito, por meio do melhoramento e desenvolvimento das condições da vida social (BARATTA, 1999, p. 35).

Apesar da evolução das teorias criminológicas e sua tentativa em mudar o enfoque de análise do fenômeno criminal, verifica-se que o discurso da defesa social nos moldes elaborados pelas Escolas Penais Clássica e Positiva permanece vivo e, cada vez mais, vem sendo utilizado para legitimar a aplicação da pena, o incremento do poder punitivo e a intensificação das atitudes intervencionistas do Estado, por vezes, levado ao extremo.

\section{O DISCURSO POLÍTICO DO COMBATE AO CRIME}

No Brasil, diante do aumento das taxas de criminalidade e da propagação sensacionalista da mídia, nota-se que os cidadãos vivem com um medo constante, fruto da insegurança pública e da sensação de impunidade transmitida pelo próprio Estado, o que gera desconforto social, além de alterar o próprio cotidiano em face do receio de tornarem-se vítimas de crimes, no meio acadêmico esse medo é comumente conhecido como fear of crime.

O medo do crime consiste na sensação da antecipação, angústia e ansiedade de se tornar vítima de infração penal (anticipation of victimization), sem haver necessariamente uma relação lógica com a realidade. Isso acarreta prejuízo significativo da qualidade de vida individual e, eventualmente, coletiva (DANTAS, SILVA JÚNIOR, PERSJIN, 2006).

O medo, fundado na percepção do perigo e de incertezas, pode pautar o comportamento humano e ser utilizado como forma de controle sobre determinados grupos ou 
pessoas, tornando a sociedade menos ativa comunitariamente e, por conseguinte, mais vulnerável à criminalidade. Nessa perspectiva, o medo é amplamente explorado (FELIX, 2009, p. 157).

[...] um medo construído socialmente, com o fim último de submeter pessoas e coletividades inteiras a interesses próprios e dos grupos, e tem sua gênese na própria dinâmica da sociedade. Produzido e construído em determinados contextos sociais e individuais, por determinados grupos ou pessoas, com vistas a atingir determinados objetivos de subjugar, dominar e controlar o outro, e grupos, através da indimidação e coerção. Esse medo leva coletividades, territorializadas em certos espaços, a temer tal ameaça advinda desses grupos (BAIERL, 2004, p. 48).

Aproveitando-se desse medo, é possível verificar que os candidatos ao governo, incluindo a presidência, têm investido no denominado "discurso político do crime" nas suas campanhas, pautado principalmente nos argumentos da defesa social e na promessa de segurança. Sob a ótica das estratégias de marketing, é indiscutível a eficácia de tal discurso.Todavia, em se tratando da eficiência do Direito Penal como instrumento de combate à criminalidade, o tempo ensina que referido discurso é um retumbante fracasso.

Nesse contexto, as eleições de 2018 refletiram, dentre outras, a insatisfação da população brasileira em permanecer no estado constante de medo do crime, apostando no candidato à presidência que possuía uma pauta conservadora e calcada em discursos repressivistas de combate ao crime, assim como na eleição expressiva de policiais e militares para cargos legislativos.

No ranking mundial da segurança, o relatório recente do instituto "Law and Order" ${ }^{3}$ que leva em conta variáveis como sensação de segurança, confiança na polícia, roubos e homicídios, o Brasil foi apontado como o quarto pior entre 142 países, sendo que a sensação de insegurança dos brasileiros apenas não superou a Venezuela, Gabão e Afeganistão.

As promessas do presidente eleito Jair Bolsonaro foram construídas com base em um ambiente social de predominância do medo e baseadas principalmente na retórica de tolerância zero, com o endurecimento das leis penais, aumento da força policial e mudanças no estatuto do desarmamento para flexibilizar o acesso à posse e ao porte de armas à população ${ }^{4}$. No mesmo trilhar repressivo, o governador eleito do Rio de Janeiro, Wilson

3 GALLUP, 2018 Global Law and Order report. Disponível em: <https://www.insightcrime.org/wpcontent/uploads/2018/06/Gallup_Global_Law_And_Order_Report_2018.pdf >.

${ }^{4}$ Propostas do candidato Jair Bolsonaro relativas à segurança pública apresentadas no plano de governo ao Tribunal Superior Eleitoral: $1^{\circ}$ Investir fortemente em equipamentos, tecnologia, inteligência e capacidade investigativa das forças Policiais; $2^{\circ}$ Prender e deixar preso! Acabar com a progressão de penas e as saídas 
Witzel defende a "política do abate" ${ }^{, 5}$ de criminosos que estejam portando armas pesadas, pois são considerados uma ameaça à paz social.

Os clamores positivistas e os discursos de ódio, pautados no aumento da intervenção estatal vêm ganhando força e demonstrando que a população prefere abrir mão de sua própria liberdade em prol da segurança, ainda que não haja garantia alguma de que o recrudescimento penal trará resultados significativos. Porém, a ideia do castigo ainda que simbolicamente representa a prevenção ao crime pelo Estado, materializando o discurso de Foucault (1987, p. 320): “A mínima desobediência é castigada e o melhor meio de evitar delitos graves é punir muito severamente as mais leves faltas".

Essa escolha remonta às ideias de Hobbes, segundo o qual para livrar os homens do estado de natureza seria necessário o estabelecimento de contratos sociais que implicam na consignação de leis morais, e, para tanto, os homens sacrificariam a sua liberdade individual em troca de segurança. Esta liberdade seria alienada ao Estado, simbolicamente representado pelo Leviatã ${ }^{6}$, que deve ser forte o suficiente para assegurar e regular comportamentos para garantia da paz e da segurança:

Que um homem concorde, quando outros também o façam, e na medida em que tal considere necessário para a paz e para a defesa de si mesmo, em renunciar a seu direito a todas as coisas, contentando-se, em relação aos outros homens, com a mesma liberdade que aos outros homens permite em relação a si mesmo (HOBBES, 1988, p. 79).

Porém, experiências de fortificação do Estado já aplicadas anteriormente provam que a redução da liberdade pode custar caro aos cidadãos. A política de tolerância zero à criminalidade, adotada na década de 90 inicialmente em Nova Iorque pelo prefeito Rudolph Giuliani, foi chamada de "Lei e Ordem" (Law and Order) e funcionou como um "cheque em branco para perseguir agressivamente a pequena delinquência e reprimir os mendigos e os sem-teto nos bairros deserdados" (WACQUANT, 1999, p. 16).

temporárias; $3^{\circ}$ Reduzir a maioridade penal para 16 anos; $4^{\circ}$ Reformular o Estatuto do Desarmamento para garantir o direito do cidadão à LEGÍTIMA DEFESA sua, de seus familiares, de sua propriedade e a de terceiros; $5^{\circ}$ Policiais precisam ter certeza que, no exercício de sua atividade profissional, serão protegidos por uma retaguarda jurídica. Garantida pelo Estado, através do excludente de ilicitude. Nós brasileiros precisamos garantir e reconhecer que a vida de um policial vale muito e seu trabalho será lembrado por todos nós! Pela Nação Brasileira; $6^{\circ}$ Tipificar como terrorismo as invasões de propriedades rurais e urbanas no território brasileiro; $7^{\circ}$ Retirar da Constituição qualquer relativização da propriedade privada, como exemplo nas restrições da EC/81; $8^{\circ}$ Redirecionamento da política de direitos humanos, priorizando a defesa das vítimas da violência. Disponível em: <http://www.tse.jus.br/eleicoes/eleicoes-2018/propostas-de-candidatos>.

${ }^{5}$ GAZETA ONLINE. Witzel volta a defender "abate de criminosos" no Rio de Janeiro. Agência Brasil. Rio de Janeiro, 14 abr. 2019.

${ }^{6}$ Monstro simbólico que representa o Estado, detentor de toda força e poder, na obra de Thomas Hobbes. 
O plano americano é reflexo do chamado direito penal máximo, segundo o qual, em síntese, todas as condutas ilícitas, por mais irrelevantes que sejam, devem ser objeto de apenamento, as penas devem ser mais longas, os regimes de cumprimento mais rígidos e as possibilidades de benefícios menores. Como conseqüência, o processo penal deve ser mais célere e utilitarista, no sentido de diminuir as garantias processuais do cidadão em nome do interesse estatal de mais rapidamente apurar e apenar condutas. Esse discurso, quando levado a cabo por políticos hábeis e demagogos, acaba gerando na população o equivocado sentimento de que o programa de tolerância zero é a solução para todos os males (LOPES JR, 2001).

Referida política foi midiaticamente difundida como a solução dos problemas para conter a criminalidade e a desordem "e com ela a retórica militar da guerra ao crime e da reconquista do espaço público, que assimila os delinquentes (reais ou imaginários), sem-teto, mendigos e outros marginais a invasores estrangeiros - o que facilita o amálgama com a imigração, sempre rendoso eleitoralmente" (WACQUANT, 1999, p. 19).

Porém, apesar da diminuição das taxas de crimes à época, não há provas de que a redução tenha ocorrido exclusivamente em razão do uso agressivo da força estatal, mas sim de uma combinação de diversos fatores, especialmente da evolução econômica e social, além do aumento da qualidade de vida e substancial decréscimo dos índices de desemprego, que levaram a resultados positivos de queda da criminalidade em todo o país e não somente em Nova Iorque (LOPES JR, 2001).

Além disso, é preciso levar em consideração os efeitos negativos causados pela política de "tolerância zero" como as prisões abusivas realizadas "pelo aspecto" (racial profiling), baseadas principalmente na aparência, comportamento e em especial cor da pele, sendo que inúmeras delas foram anuladas de plano ou declaradas sem motivo pela corte posteriormente, o que resultou na sobrecarga de tribunais e departamentos prisionais, além da violação sistemática de direitos constitucionais (WACQUANT, 1999, p. 23-26).

É importante observar que a legitimação do Estado como poder soberano capaz de exercer discricionariamente a força para conter a violência pode ser utilizada como pano de fundo para segregar aqueles tidos como indesejados socialmente, violando direitos fundamentais já conquistados. "Sacrificam-se direitos fundamentais em nome da incompetência estatal em resolver os problemas que realmente geram a violência” (LOPES JR, 2001).

Nesse contexto, verifica-se que o aumento do poder punitivo do Estado aumenta a seletividade penal, pois, por mais que se busque normas jurídicas de caráter geral, abstrato e 
não discriminatório, é certo que sua aplicação não será livre de conceitos ou preconceitos, intuições, preferências, hábitos ou experiências, pois dependem da ação e interpretação de seres humanos, sujeitos a todas estas influências subjetivas. Ao atuar em nome do Estado, único detentor do jus puniendi, o sujeito deve se obrigar a agir com imparcialidade, mas partindo-se de uma análise moral, sabe-se que a total isenção e imparcialidade é um ideal árduo a ser atingido.

Desse mecanismo, emerge, com nitidez, que os contornos históricos e sociológicos da construção da imagem do elemento suspeito são decisivos nas abordagens policiais e revela a relação direta com a tendência criminalizadora das minorias estigmatizadas:

Através da análise externa efetuada pela Criminologia Crítica, (onde o sistema penal
passa ser objeto de seu estudo) o que se evidenciou foi a seletividade com que é
manifesta o poder punitivo do Estado. Este não atua de forma racional, buscando a
aplicação igualitária da lei penal ao caso concreto. Ao contrário, seleciona
indivíduos de classes baixas da sociedade para serem rotulados como criminosos
com o intuito de ocultar a criminalidade daqueles que detêm o poder econômico.
(RODRIGUES, 2003, p.123)

$\mathrm{Na}$ esteira do atual governo, é possível verificar, nas recorrentes notícias que envolvem a morte de inocentes por forças policiais, sinais de um aumento da violência e não redução, porém, agora uniformizada e institucionalizada. A título exemplificativo cabe citar o recente caso em que carro do músico Evaldo dos Santos Rosa, morto por militares do Exército ao se dirigir para um chá de bebê com sua família, foi atingido por 80 tiros de fuzil. ${ }^{7}$ No mesmo sentido, foi a morte do jovem 19 anos, Christian Felipe Santana, que ao furar um bloqueio policial foi morto com um tiro nas costas pelo Exército, sem qualquer possibilidade de reação. ${ }^{8}$ Também no Rio de Janeiro, uma operação recente da polícia militar em uma favela resultou em 14 mortes, que segundo familiares possuíam indícios de execução, pois ocorreram após a rendição das vítimas. ${ }^{9}$ Em todas elas há um elemento comum referente à cor das vítimas, bem como a maioria dos casos ocorrem em regiões periféricas das cidades.

A crença de que o controle social formal solucionará os problemas relativos à criminalidade é uma ilusão, a própria criminologia aponta que o controle social mais efetivo é o informal. Se esse discurso se efetivar na prática e o governo passar a se empenhar mais em

\footnotetext{
${ }^{7}$ G1 Rio por TV Globo. Homem morre após ser baleado em ação do Exército na Zona Oeste do Rio. Rio de Janeiro, 07 abr. 2019.

${ }^{8}$ G1 por RJ2. Jovem de 19 anos que morreu após furar bloqueio do Exército no Rio é enterrado. Rio de Janeiro, 06 abr. 2019.

${ }^{9}$ G1 por Jornal Nacional. No Rio, polícia e MP investigam ação da PM com 15 mortos no Morro do Fallet. Rio de Janeiro, 14 fev. 2019.
} 
segurança do que nos demais campos sociais carentes de investimento como na educação e enfrentamento da pobreza, em alguns anos teremos um crescimento desenfreado da população carcerária. Sobre esse papel simbólico do Direito Penal, discorre Greco:

[...] o caráter simbólico de um Direito Penal que procura ocupar o papel de educador da sociedade, a fim de encobrir o grave e desastroso defeito do Estado, que não consegue cumprir suas funções sociais, permitindo que, cada dia mais, ocorra um abismo econômico entre as classes sociais, aumentando assim, o nível de descontentamento e revolta da população mais carente, agravando, consequentemente, o número de infrações penais aparentes, que, a seu turno, causam desconforto, à comunidade, que por sua vez, começam a clamar por mais justiça. $\mathrm{O}$ círculo vicioso não tem fim (GRECO, 2009, p. 17).

Se a maior parte da população opta livremente por não praticar crimes, significa que o controle social informal assegurado por meio da estrutura familiar, educação, emprego, foi efetivo em sua vida, fazendo com que a escolha pela vida correta fosse espontânea. Por outro lado, se a base não funcionar e o Estado passar a dar maior importância para o controle repressivo ao invés do preventivo, naturalmente a escolha pelo caminho do crime crescerá e consequentemente o acúmulo de presos também.

O sociólogo Tiago Ivo Odon ao analisar os riscos de se importar teorias e políticas levanta um questionamento essencial para a reflexão da realidade brasileira e a possibilidade de um aumento da violência ao invés da almejada redução: "Um policiamento agressivo do tipo "tolerância zero" dirigido ao brasileiro com baixa capacidade de autogoverno, que dificilmente toma a iniciativa e que tende a resolver seus conflitos mais por meio do uso da agressão do que da razão, tenderia a gerar mais ou menos violência?” (ODON, 2016, p. 17).

Obviamente a solução também não seria a adoção de um estado mínimo, ao menos não em uma país que carece materialmente de tantos direitos sociais, mas a compensação das desigualdades e ausência de estrutura básica para efetivação dos direitos fundamentais, como é o caso da segurança, não pode ser compensada com excessos de criminalização:

Exsurge daí a falácia da ideologia do Estado mínimo, pois ao Estado neoliberal
mínimo no campo social e da cidadania passa a corresponder um Estado máximo,
onipresente e espetacular no campo penal. Os deficits de dívida social e de cidadania
são ampla e verticalmente compensados com excessos de criminalização; os deficits
de terras, moradias, estradas, ruas, empregos, escolas, creches e hospitais
compensados com multiplicação de prisões; a instrumentalidade da Constituição,
das leis e dos direitos sociais, pelo simbolismo da lei penal; a potencialização da
cidadania pela vulnerabilidade à criminalização (ao etiquetamento pela desordem e
pela criminalidade) (ANDRADE, 2013, p. 342).

Apesar de não haver uma solução pontual para o obstáculo da criminalidade é patente a constatação de que a raiz do problema tem origem na desigualdade social e na falta 
de oportunidades, pois quanto mais uma sociedade é desigual, mais há a necessidade de um sistema de controle social do desvio de tipo repressivo. Numa sociedade livre e igualitária, além da substituição da gestão autoritária pela social, o próprio conceito de desvio perde progressivamente a sua conotação estigmatizante. Nesse contexto, ressalta-se a lição de Baratta: "Nós sabemos que substituir o direito penal por qualquer coisa melhor somente poderá acontecer quando substituirmos a nossa sociedade por uma sociedade melhor" (BARATTA, 1999, p. 206-207).

Por todo o exposto, infere-se que sempre haverá justificativas para a ampliação da tutela penal e do controle repressivo, notadamente em países como o Brasil de desenvolvimento tardio, onde imperam a desigualdade e a insegurança, porém, políticas de repressão, pautadas na clássica ideologia da defesa social, acabam produzindo efeitos contrários e atuando como combustível da violência. A busca por um direito penal e gerência estatal fundado na efetivação das garantias fundamentais e nas premissas do Estado Democrático de Direito é a única via para a almejada mudança de cenário.

\section{CONSIDERAÇÕES FINAIS}

O caminho mais eficaz para a solução da problemática relativa à violência consistiria na realização de uma mudança profunda no aparato de segurança, investimento no sistema de justiça e execução da pena, reforma das normas e sanções penais. Porém, o que se observa é um nítido crescimento do populismo penal, na contramão da ressocialização e das políticas públicas de reinserção social do criminoso.

O Estado Democrático de Direito não permite a eliminação ou segregação permanente daqueles considerados inimigos do Estado por descumprirem normas penais, diante disso, o endurecimento das leis e castigos e as falácias dos discursos repressivos servem apenas para alimentar aqueles que têm ânsia de vingança e querem dirimir a problemática de forma imediatista e ineficaz.

Essa onda punitivista deve muito de sua influência à mídia e aos discursos retomados pelo governo nas últimas eleições. Com uma pauta de promessas infundadas os políticos exploram o medo e a insegurança da população para angariar votos e construir suas campanhas fundamentados por discursos de ódio e autoritarismo, seguindo as diretrizes de teorias utilizadas em outros países como a política da Lei e Ordem e da Tolerância Zero, que outrora já se mostraram ineficientes e autoritárias. 
O Brasil, considerado um país de desenvolvimento tardio, têm altos índices de criminalidade que estão diretamente associados à desigualdade social, falta de oportunidades, desemprego, educação de má qualidade, entre outros direitos sociais básicos que são privados à grande parte da população. O controle social exercido pelos agentes de controle informais surte mais efeito do que qualquer punição fixada em lei ou aplicada pelos agentes formais de controle do Estado. Ao contrário do que se espera, o aumento da violência tende a gerar mais violência, bem como acentua a desigualdade ao destacar a seletividade do sistema punitivo no que concerne às classes menos favorecidas.

Diante do exposto, conclui-se que a atenção do governo pode estar direcionada para problemas que não serão facilmente resolvidos com políticas de repressão e inflacionamento penal. É preciso, pois, conscientizar a sociedade para repensar os fundamentos do próprio direito, no sentido de que os anseios sociais de justiça não serão solucionados desta forma e a fim de que tais discursos não se transformem em práticas legítimas a ponto de retirarem a liberdade e se voltarem contra os próprios cidadãos.

\section{REFERÊNCIAS}

ANDRADE, Vera Regina Pereira de. A ilusão de segurança jurídica: do controle da violência à violência do controle penal. $3^{\mathrm{a}}$ Ed. Porto Alegre: Livraria do Advogado, 2015.

ANDRADE, Vera Regina Pereira de. Mudança do Paradigma Repressivo em Segurança Pública: reflexões criminológicas críticas em torno da proposta da $1^{\circ}$ Conferência Nacional Brasileira de Segurança Pública. Seqüência (Florianópolis), n. 67, p. 335-356, dez. 2013. Disponível em: < http://www.scielo.br/pdf/seq/n67/13.pdf>. Acesso em 09 abr. 2019.

ANITUA, Gabriel Ignácio. Histórias dos pensamentos criminológicos. Rio de Janeiro: Revan, 2008.

ASHTON, Peter Walter. As principais teorias de direito penal, seus proponentes e seu desenvolvimento na Alemanha. Revista da Faculdade de Direito da UFRGS, v. 12, p. 237 246, 1996. Disponível em: <https://seer.ufrgs.br/revfacdir/article/download/69184/39073>. Acesso em 09 abr. 2019.

BAIERL, Luzia Fátima. Medo social: da violência visível ao invisível da violência. São Paulo: Editora Cortez, 2004.

BARATTA, Alessandro. Criminologia crítica e crítica do direito penal. Tradução: Juarez Cirino dos Santos. 2.ed. Rio de Janeiro: Freitas Bastos: Instituto Carioca de Criminologia, 1999.

BECCARIA, Cesare. Dos delitos e das penas. Tradução: Torrieri Guimarães. São Paulo: Editora Martin Claret, 2007. 
BITENCOURT, Cezar Roberto. Falência da pena de prisão: causas e alternativas. $4^{\mathrm{a}}$ ed. São Paulo: Saraiva, 2011.

CARVALHO, Salo de. Antimanual de criminologia. 6ª ed. São Paulo: Saraiva, 2014.

DANTAS, George Felipe de Lima; SILVA JÚNIOR, Álvaro Pereira da; PERSIJN, Annik. O Medo do Crime. 2006. Disponível em:

<http://www.observatorioseguranca.org/pdf/01\%20(60).pdf>. Acesso em: 07 abr. 2019.

FELIX, Sueli Andruccioli. Crime, medo e percepções de insegurança. Perspectivas, São Paulo, v. 36, p. 155-173, jul./dez. 2009. Disponível em:

<https://periodicos.fclar.unesp.br/perspectivas/article/view/2750/2488>. Acesso em 07 abr. 2019.

FOUCAULT, Michel. Vigiar e punir: nascimento da prisão; tradução de Raquel Ramalhete. Petrópolis: Vozes, 1987.

GALLUP, 2018. Global Law and Order report. Disponível em:

<https://www.insightcrime.org/wp-

content/uploads/2018/06/Gallup_Global_Law_And_Order_Report_2018.pdf>. Acesso em 11 abr. 2019.

GAZETA ONLINE. Witzel volta a defender "abate de criminosos" no Rio de Janeiro. Agência Brasil. Rio de Janeiro, 14 abr. 2019. Disponível em: <

https://www.gazetaonline.com.br/noticias/politica/2019/01/witzel-volta-a-defender-abate-decriminosos-no-rio-de-janeiro-1014163442.html>. Acesso em: 14 abr. 2019.

G1 Rio por TV Globo. Homem morre após ser baleado em ação do Exército na Zona Oeste do Rio. Rio de Janeiro, 07 abr. 2019. Disponível em: < https://g1.globo.com/rj/rio-dejaneiro/noticia/2019/04/07/homem-morre-apos-carro-ser-atingido-em-acao-do-exercito-nazona-oeste-do-rio.ghtml>. Acesso em 10 abr. 2019.

G1 por RJ2. Jovem de 19 anos que morreu após furar bloqueio do Exército no Rio é enterrado. Rio de Janeiro, 06 abr. 2019. Disponível em: < https://g1.globo.com/rj/rio-dejaneiro/noticia/2019/04/06/jovem-de-19-anos-que-morreu-apos-furar-bloqueio-do-exercitono-rio-e-enterrado.ghtml>. Acesso em 10 abr. 2019.

G1 por Jornal Nacional. No Rio, polícia e MP investigam ação da PM com 15 mortos no Morro do Fallet. Rio de Janeiro, 14 fev. 2019. Disponível em: <https://g1.globo.com/jornalnacional/noticia/2019/02/14/no-rio-policia-e-mp-investigam-acao-da-pm-com-15-mortos-nomorro-do-fallet.ghtml>. Acesso em 10 abr. 2019.

GOMES, Geder Luiz Rocha. O conflito entre a defesa social e o respeito às garantias fundamentais. Revista Jurídica. Unifacs. Salvador, 2008. Disponível em: < https://www.unifacs.br/revistajuridica/arquivo/edicao_junho2008/convidados/con3.pdf>. Acesso em: 09 jan. 2019.

GRECO, Rogério. Direito Penal do equilíbrio: uma visão minimalista do Direito Penal. 4. Ed. Niterói, Rio de Janeiro: Impetus, 2009.

HOBBES, Thomas. Leviatã. Matéria, forma e poder de um Estado eclesiástico e civil. (Tradução de João Paulo Monteiro e Maria Beatriz Nizza da Silva). 3. ed. São Paulo: AbrilCultural, 1983. Col. Os Pensadores. 
JAKOBS, Günter, MELIÁ, Manuel Cancio. Direito Penal do Inimigo - Noções e Críticas. Porto Alegre: Livraria do Advogado, 2005.

LOPES JR, Aury. Violência urbana e tolerância zero: Verdades e mentira. Âmbito Jurídico, Rio Grande, II, n. 5, maio 2001. Disponível em < http://www.ambitojuridico.com.br/site/index.php?n_link=revista_artigos_leitura\&artigo_id=5805>. Acesso em: 07 abr. 2019.

LYRA, Roberto. Novíssimas escolas penais. Rio de Janeiro: Borsoi, 1956

FREITAS, Renato Alexandre da Silva; MISAKA, Marcelo Yukio; VALLE, Nathália do. Uma reflexão crítica aos movimentos de Lei e Ordem - Teoria das Janelas Quebradas. Revista Juris UniToledo, Araçatuba, SP, v. 03, n. 04, p.146-162, out./dez. 2018. Disponível em: < http://ojs.toledo.br/index.php/direito/article/view/3055/380>. Acesso em 07 abr. 2019.

ODON, Tiago Ivo. Tolerância zero e janelas quebradas: sobre o risco de se importar teorias e políticas. Brasília: Núcleo de Estudos e Pesquisas/CONLEG/Senado, março/2016. Disponível em: <www.senado.leg.br/estudos>. Acesso em 09 abr. 2019.

OLIVEIRA, Fernando Antônio Sodré de. Breves apontamentos sobre as políticas criminais e sua influência nos mecanismos de controle social formal. Revista Direito em Debate. vol. 18, n. ${ }^{o}$ 31, jan.-jun. 2009. Disponível em: <https://doi.org/10.21527/2176-6622.2009.31.\%p〉. Acesso em 05 abr. 2019.

PAVARINI, Massimo. Control y dominación. Teorías criminológicas burguesas y proyecto hegemónico. Tradução por Ignaci Munagorri. México: Siglo Veintiuno, 1988.

RODRIGUES, Saulo Tarso. Criminologia - A política criminal alternativa e os princípios de direito penal mínimo de Alessandro Baratta: na busca da (re) legitimação do sistema. São Paulo: Editora Sisan, 2003.

ROXIN, Claus. Estudos de direito penal. Tradução de Luiz Greco. Rio de Janeiro: Renovar, 2006.

RUSCHE, Georg; KIRCHHERIMER, Otto. Punição e estrutura social. $2^{\mathrm{a}}$ ed. Rio de Janeiro: Editora Revan, 2004.

SANTOS, Bartira Macedo de Miranda. As ideias de defesa social no sistema penal brasileiro: entre o garantismo e a repressão (de 1890 a 1940). Tese apresentada no Programa de Estudos Pós-Graduados em História da Ciência na Pontifícia Universidade Católica de São Paulo, 2010.

SHECAIRA, Sérgio Salomão. Criminologia. 5 ed. ver. - São Paulo: Editora Revista dos Tribunais, 2013.

WACQUANT, Loïc. As prisões da miséria. Tradução: André Telles. Rio de Janeiro: Jorge Zahar, 1999.

ZAFFARONI, Eugenio Raúl. Em busca das penas perdidas: a perda da legitimidade do sistema penal. Tradução: Vania Romao Pedrosa, Amir Lopez da Conceição. Rio de Janeiro: Revan, 2017. 